\title{
Variation in use of antipsychotic medications in nursing homes in the United States: A systematic review
}

\author{
Hannah Cioltan ${ }^{1,2^{*}} \mathbb{D}$, Samah Alshehri ${ }^{3}$, Carol Howe ${ }^{4}$, Jeannie Lee ${ }^{2,3}$, Mindy Fain ${ }^{2,5}$, Howard Eng ${ }^{1,3}$, \\ Kenneth Schachter ${ }^{1}$ and Jane Mohler ${ }^{1,2,3,5}$
}

\begin{abstract}
Background: The use of antipsychotic medications (APMs) in nursing home residents in the U.S. is an increasingly prominent issue and has been associated with increased risk of hospitalization, cardiovascular events, hip fractures, and mortality, among other adverse health events. The Food and Drug Administration has placed a black box warning on these drugs, specifying that they are not meant for residents with dementia, and has asked providers to review their treatment plans. The purpose of this systematic PRISMA (Preferred Reporting Items for Systematic Reviews and Meta-analyses)-based review was to summarize original research studies on facility level characteristics contributing to the use of antipsychotics in nursing homes across the United States, in order to investigate the variation of use.

Methods: We searched Ovid Medline, Embase, Cochrane Library, Web of Science, CINAHL, Psyclnfo, and Sociological Abstracts. Articles were selected according to the following criteria: (1) Population of interest: older adults ( $\geq 60$ years of age) residing in nursing homes (not home-based or inpatient hospital settings) in the U.S. (2) Receiving APMs, typical and/or atypical. Specifically excluded were studies of psychotropic medications such as antidepressants, benzodiazepines, anxiolytics, hypnotics, mood stabilizers, and stimulants. All study designs were considered, though reviews, editorials, letters to the editor and opinion pieces were excluded. An expert consultant panel was consulted to categorize facility characteristics into domains and determine possible etiologies of APM use based upon each characteristic.
\end{abstract}

Results: Nineteen observational studies, both quantitative and qualitative, published from 2000 to 2015, met full inclusion criteria and were included in this review. APM use varied based on multiple facility characteristics across several domains: 1) physical, 2) staffing, 3) occupancy, 4) market, and 5) quality.

Conclusions: Variation in use of APMs in U.S. nursing homes based upon facility characteristics exemplifies the need for a more systematic protocol guiding the use of these medications, along with heightened regulatory policies and enforcement.

Keywords: Antipsychotics, Nursing homes, Dementia, Behavioral symptoms

\footnotetext{
* Correspondence: hstocker@aging.arizona.edu

${ }^{1}$ College of Public Health, University of Arizona, Tucson, Arizona, USA

${ }^{2}$ Arizona Center on Aging, College of Medicine, University of Arizona, Tucson,

Arizona, USA

Full list of author information is available at the end of the article
} 


\section{Background}

The 1987 Omnibus Budget Reconciliation Act's Nursing Home Reform Law, was enacted to improve patientcentered nursing home care quality, and included standards regarding freedom from unnecessary drugging; freedom from chemical restraints; and rights to be informed about, participate in, and refuse treatment [1].In 2005, the Food and Drug Administration (FDA) placed a black box warning on antipsychotic medications (APMs) use in elderly patients because of the dangerous health outcomes associated with use including mortality [2]. In a 2011 report from the Office of Inspector General, it was determined $83 \%$ of Medicare claims for APMs in nursing home residents were associated with off-label conditions [3]. Following this, in March 2012, the Centers for Medicare and Medicaid Services (CMS) launched an education and training, and oversight and provider accountability initiative targeted to provide appropriate, resident-centered dementia care to decrease the use of APMs in nursing homes nationwide by $15 \%$. CMS added two quality measures on the Nursing Home Compare website related to APMs including the percent of long-stay residents who received an APM [4]. Despite these gains, APM use in elderly nursing home patients has continued, with 1 in 5 nursing home residents treated with APMs [5]. This problem will only grow in magnitude if not addressed. By 2050 the population of older adults aged 65 and older is projected to reach 83.7 million, almost doubling the estimated 2012 elder population of 43.1 million [6]. In 2012 15,700 nursing homes served 1.4 million residents; the number of elders residing in nursing homes will only increase with our increasing older population [7].

APMs are approved by the FDA for the treatment of schizophrenia and/or bipolar disorder but are increasingly used to treat the behavioral symptoms of dementia, an off-label use [3]. In the years between 1995 and 2008 such off-label use more than doubled [8]. The effectiveness of APMs for off-label use to treat behavioral symptoms of dementia is not supported by strong evidence and the use of APMs in patients with dementia increases the risk of adverse health events with little evidence of effectiveness $[9,10]$.

The use of APMs is not only a concern in the U.S. but also internationally. In the United Kingdom, a study including 12 nursing homes found $48 \%$ of patients with dementia were prescribed APMs [11], while a provider of pharmaceutical market information showed that $20.3 \%$ of patients with dementia had a prescription for APMs [12]. A report for the Minister of State for Care Services in the United Kingdom called for a national campaign to reduce APM use, citing the limited positive and significant harm causing effects of the drugs [13]. These drugs are also commonly used in the treatment of dementia in nursing homes across western Europe with rates ranging from 12 to $59 \%$, although the clinical guidelines and warnings from European and national drug agencies suggest lowering use in this population [14]. Initiatives to reduce the use of APMs in the treatment of patients with dementia are increasingly prevalent in the U.S. and abroad-spurred by the continued high rates of use of these agents.

Adverse health outcomes associated with APM use in the elderly population include increased risk of falls, hospitalizations, cerebrovascular events, sudden cardiac death, and mortality [15]. APM use in patients with dementia is associated with a significant increased risk of stroke (OR, 3.12), cardiovascular symptoms, edema, and vasodilatation [15]. Also, the rate of sudden cardiac death among atypical antipsychotic users compared to nonusers is higher with an adjusted incidence-rate ratio of 2.26 [16]. It is vital that we reduce unnecessary use in this population because of the association between APM use and all-cause mortality. A meta-analysis of 15 randomized control trials, with 3,353 patients randomized to APMs and 1,757 randomized to placebo, showed that death occurred more frequently during the study period in patients randomized to APMs (OR, 1.54) with a number needed to harm of 100 [17].

Although previous legislation has aimed to reduce offlabel use of APMs in elderly nursing home residents, prevalence remains high. It is crucial that facility level factors associated with APM use in this population be identified and understood in order to be able to recommend interventions to decrease dangerous use in an efficient an effective manner. The purpose of this systematic review was to summarize original research studies on the facility level characteristics contributing to the use of APMs in nursing homes across the U.S.

\section{Methods \\ Study selection}

A literature review was planned and performed using methods specified in the Preferred Reporting Items for Systematic Reviews and Meta-Analyses (PRISMA) statement for reporting systematic reviews and meta-analyses however a meta-analysis was not performed [18]. Both controlled vocabulary terms (e.g., MeSH) and key words were utilized to search the following databases Ovid/ MEDLINE (1946-2015); Elsevier/Embase (1947-2015); Wiley/Cochrane Library (1898-2015); ThomsonReuters/Web of Science (1898-2015); EBSCO/PsycINFO (1880's-2015); EBSCO/CINAHL (1937-2015); and ProQuest/Sociological Abstracts (1952-2015). Literature searches were completed on July 10, 2015. The complete Ovid/MEDLINE search strategy, analogous to the other database searches, is available in Additional file 1. Reference lists of, and citations to, the articles eventually 
selected from the database searches were also screened. Only English language publications were selected and, in the case of both CINAHL and PsycInfo, article types were limited to Academic Journals and Dissertations.

Included studies focused on population of interest: 1) older adults ( $\geq 60$ years of age) residing in nursing homes (not home-based or inpatient hospital settings) in the U.S.; and 2) those who received APMs, typical and/or atypical. Specifically excluded were studies of psychotropic medications such as antidepressants, benzodiazepines, anxiolytics, hypnotics, mood stabilizers, and stimulants alone or in combination with APMs where the antipsychotic component could not be isolated. All study designs were considered although reviews, editorials, letters to the editor and opinion pieces were excluded. No publication or language limits were applied, though ultimately only articles in English were selected. Nursing homes were defined as facilities recognized by the Medicare and Medicaid systems offering skilled nursing care including rehabilitation and various medical and nursing procedures.

Titles and abstracts of retrieved references were screened for relevance by two independent reviewers ( $\mathrm{HC}$ and $\mathrm{SA}$ ), one trained in public health and gerontology, and the other in gero-pharmacy. In case of disagreements, a third reviewer $(\mathrm{CH})$ cast the deciding vote. In the same fashion, the full texts of the potential studies were further analyzed by two independent reviewers ( $\mathrm{HC}$ and SA) to see if they fully met inclusion criteria. Disagreements at this stage were resolved by consensus and in consultation with a third reviewer $(\mathrm{CH})$.

\section{Data extraction}

The reviewers ( $\mathrm{HC}$ and $\mathrm{SA}$ ) extracted the following data from the included articles: type and number of subjects, study design, the year of publication, journal of publication, U.S. regions included in the assessment, and the facility characteristics associated with the use of APMs. The summary outcome measure considered for this review was any association between facility characteristic and APM use.

\section{Quality assessment}

The selection process ensured that all articles included in the analysis were from peer-reviewed journals. All observational cross-sectional or cohort studies were assessed for alignment with the Strengthening the Reporting of Observational Studies in Epidemiology (STROBE) statement to enhance rigor [19].

\section{Data analysis}

The facility characteristics shown to have an effect on the use of APMs were categorized into domains based upon categorization found in the included studies and through iterative content analysis with expert feedback from a nursing home expert consensus group of 20 experts comprised of nursing home administrators, pharmacists, an epidemiologist, a neurologist, two geriatricians, a nursing home medical director, a nursing home nurse educator, and Healthy Brain Research Network Collaborating Centers in five states (Table 1). The facility characteristics considered were extracted from the included studies. A modified Delphi method was used to ensure structure in categorizing the characteristics into domains as well as determining the possible etiologies of APM use based on each facility characteristic contributing to use. The rationale for increased APM use was also extracted from the studies when available.

\section{Results}

Study selection

We found 8,164 studies through database searches. Citation analysis of the most relevant articles revealed an additional 15 articles. Of the 5,704 articles that remained after duplicates were removed, 5,641 were excluded because of irrelevance to the topic (Fig. 1). Strict inclusion criteria, as outlined above, were applied to the full text of 63 articles. Of these, 19 met the full set of criteria (Table 2) [20-38]. All articles were published between 2000 and 2015, during which time there were several legislative, regulatory and policy changes related to use of antipsychotics as discussed in the Background Section. Please see Additional file 2 for completed PRISMA checklist.

\section{Study design and quality assessment}

All 19 peer-reviewed articles were observational (either cross-sectional or cohort studies) or qualitative, from entities including: the Journal of the American Medical

Table 1 Expert panel details

\begin{tabular}{ll}
\hline Expert & Profession \\
\hline Jeannie Lee & Geriatric pharmacist \\
Howard Eng & $\begin{array}{l}\text { Pharmacist/health } \\
\text { services researcher } \\
\text { Gerontologist/ } \\
\text { epidemiologist }\end{array}$ \\
Jane Mohler & Geriatrician/nursing \\
Scott Bolhack & home medical director \\
Mindy Fain & Geriatrician \\
Debbie Dyjak & RN educator in nursing \\
& home \\
Lee Olitsky & Nursing home \\
Beverly Heasley & administrator \\
& Nursing home \\
University of Arizona, University of Washington, & administrator \\
University of Pennsylvania, University of South & Network \\
Carolina, Oregon Health and Science University, & Collaborating Centers \\
and University of Illinois at Chicago & \\
\hline
\end{tabular}




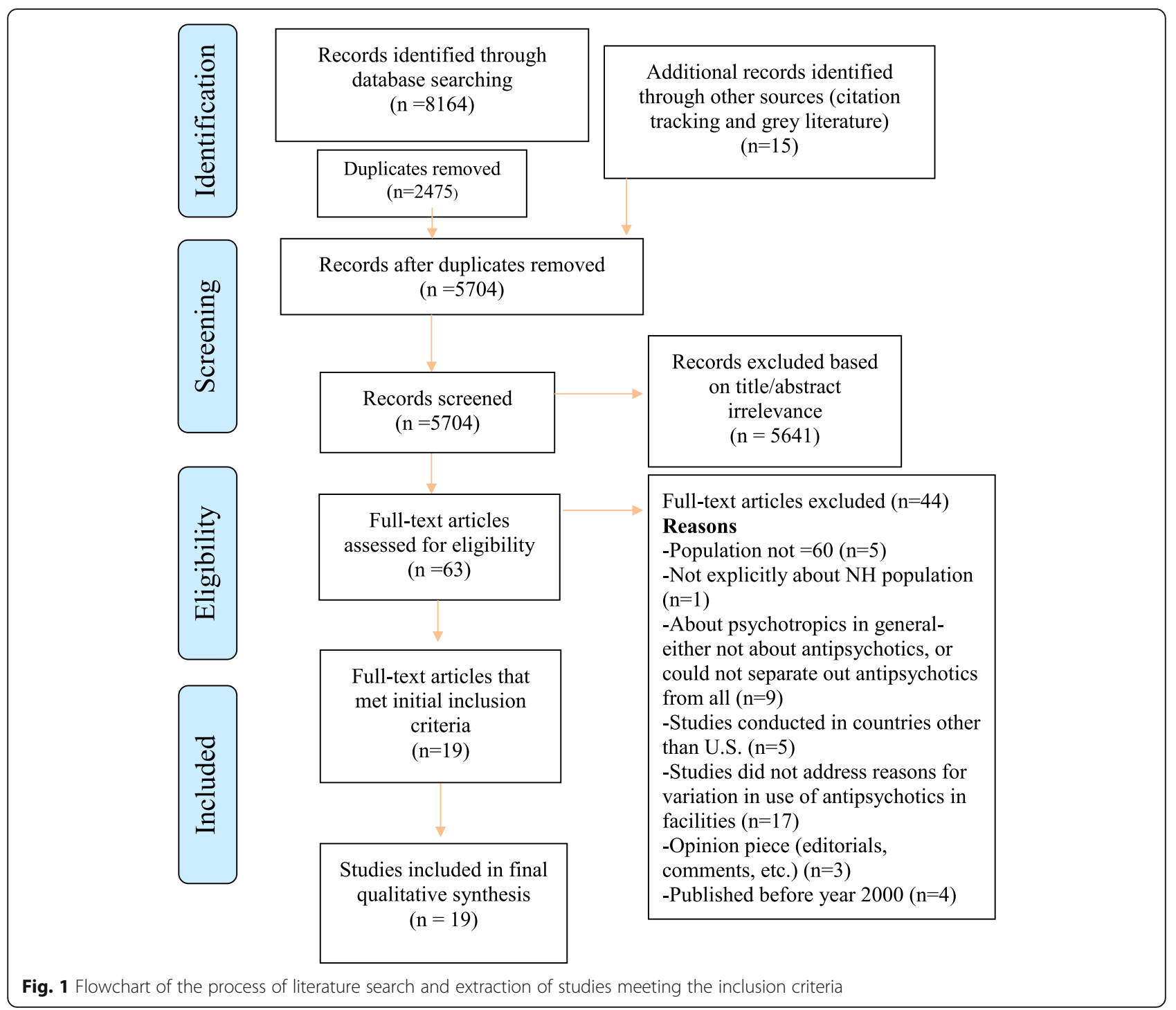

Association; the Journal of the American Geriatrics Society; the American Journal of Public Health; Drugs \& Aging; Health Economics; Journal of Health and Social Policy; among several others. The included observational studies consisted of cross-sectional, retrospective cohort and longitudinal studies by design. The specific outcome measures included: differences of APM use in nursing homes based upon facility characteristics ([20$23,25,27,31,33,34,36-38]$; odds ratios ([24, 28-30, $32,33,35]$; beta values [26]; and risk ratios [25]. The articles included aligned with the STROBE statement on what should be included in a report of an observational study [19].

\section{Subjects and representative sample}

The sample sizes ranged from 204 to 155,095 participants and 16 to 17,213 nursing homes (Table 2). All participants were nursing home residents aged 60 years or older. Many of the studies used the Online Survey, Certification and Reporting (OSCAR) database or the Minimum Data Set (MDS). MDS and OSCAR are two national systems that collect nursing home quality information required by CMS. MDS collects information about nursing home residents and OSCAR about the facility [39].

\section{Facility characteristics associated with APM use}

Table 3 depicts the characteristics associated with use of APMs: 1) physical facility characteristics such as geographic location; 2) staffing characteristics including staff to patient ratios and type of staffing; 3 ) occupancy characteristics such as occupancy rate; 4) market characteristics such as the presence of competition; and 5) quality characteristics, for example, the regulatory reporting of physical restraint use. 


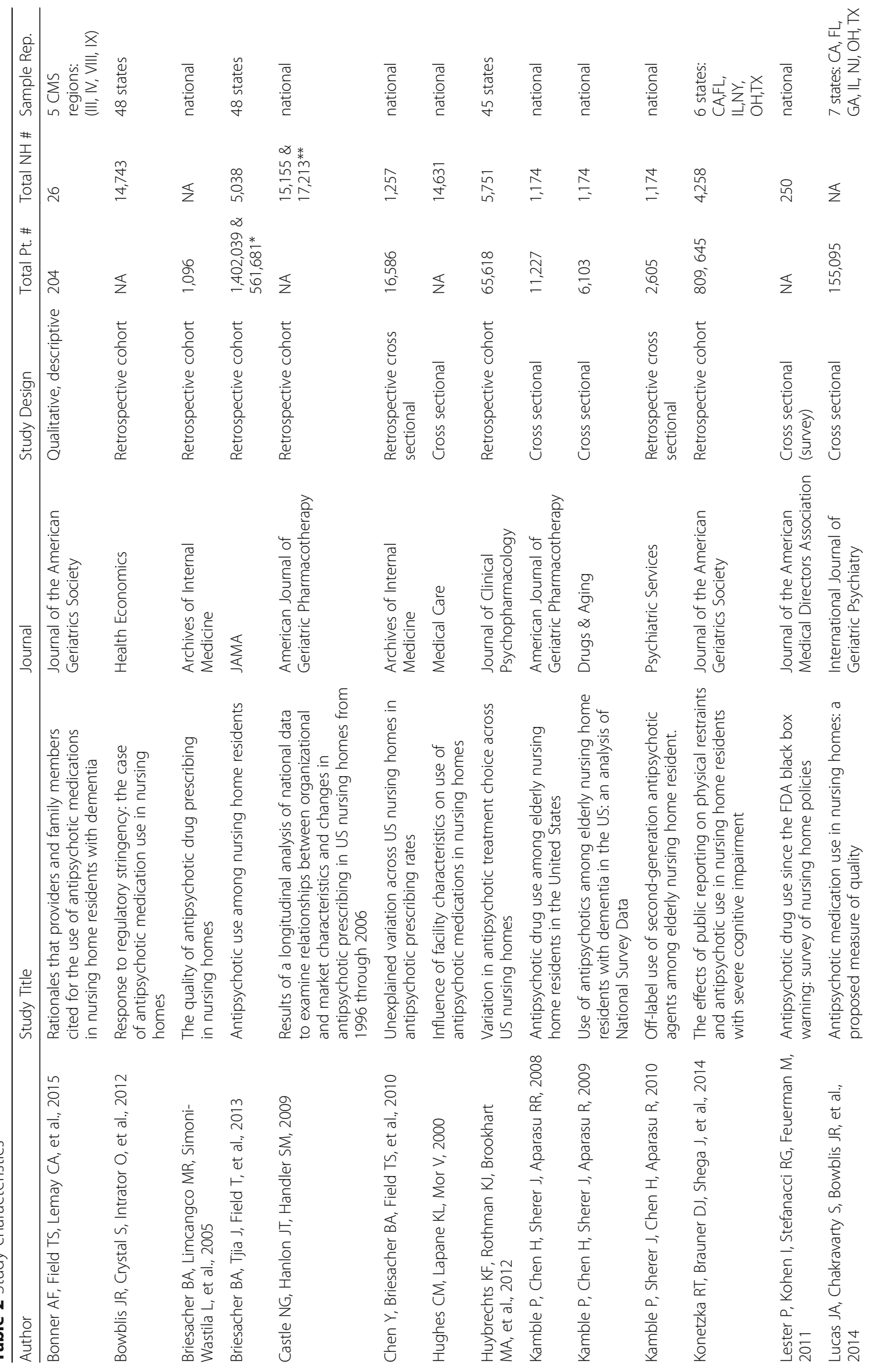




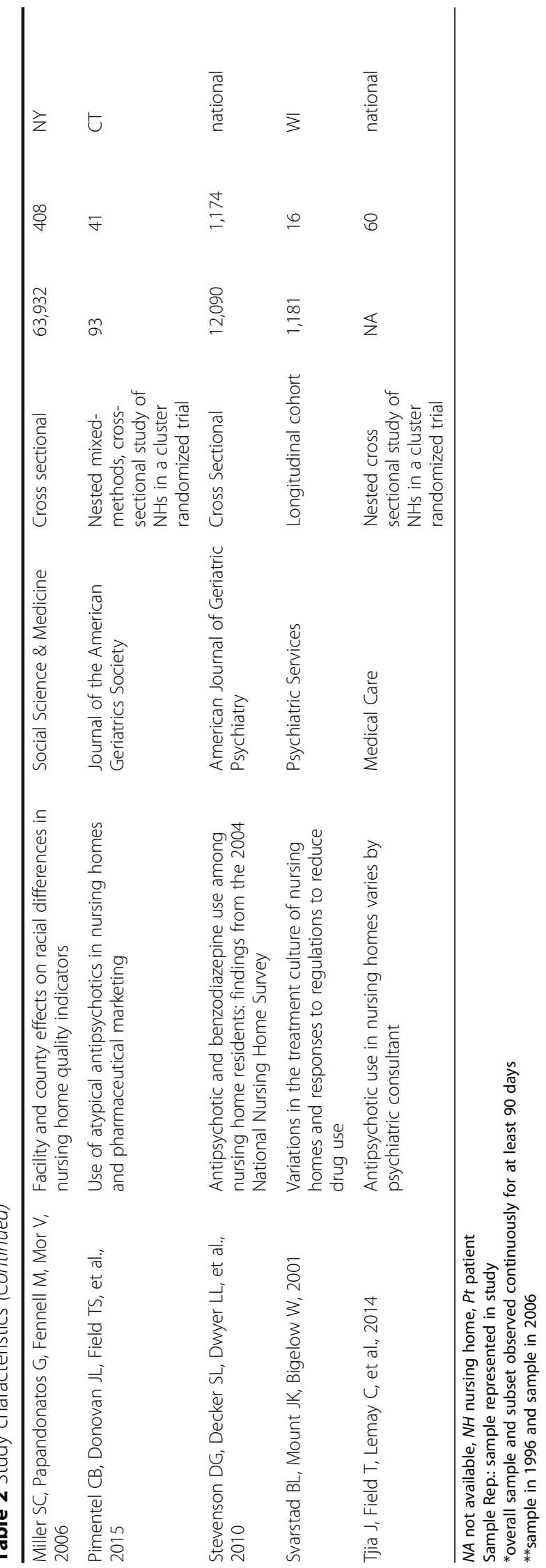




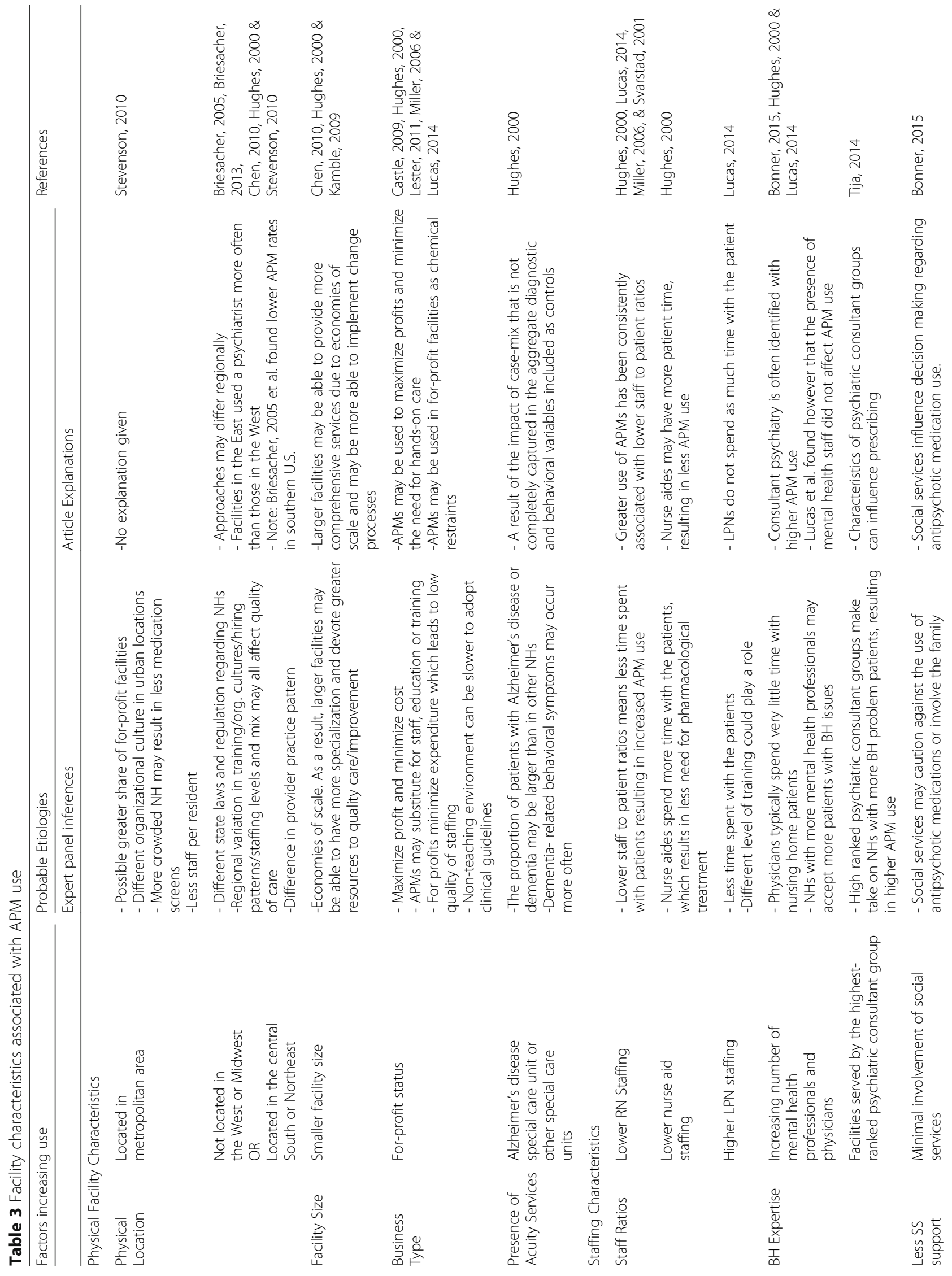




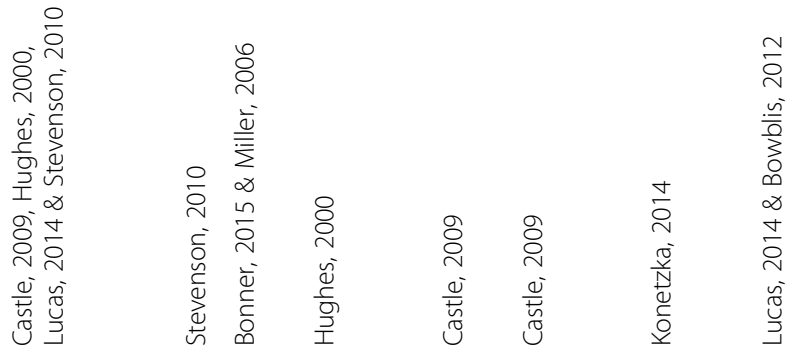

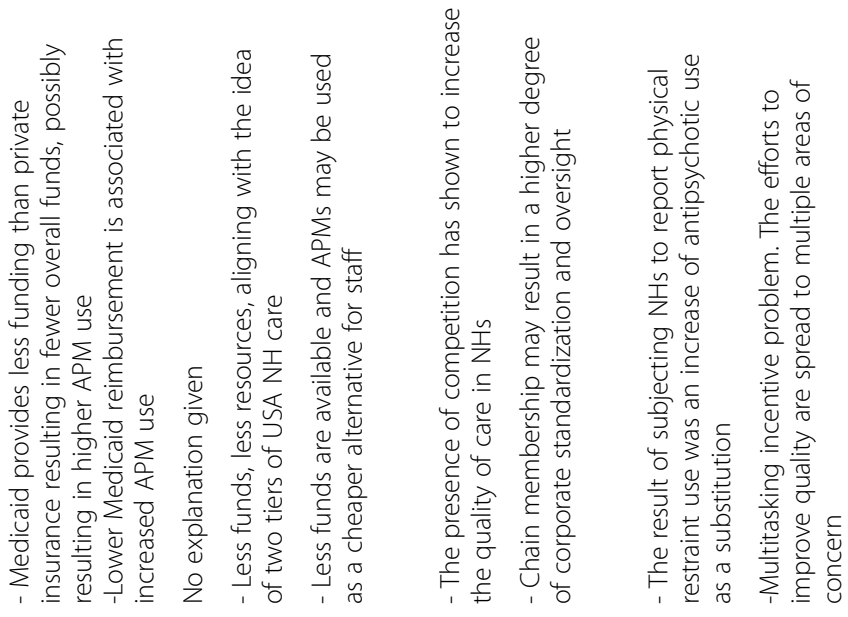

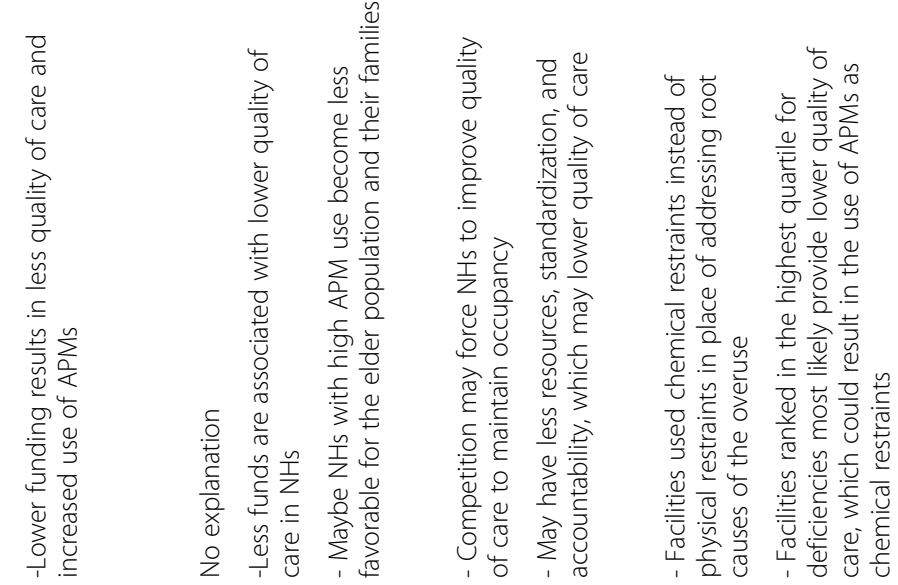

. 
The physical characteristics associated with use of APMs were: 1) physical location, specifically whether the facility was in an urban setting or not and/or its specific geographic location in the country; 2) facility size; 3 ) profit status; and 4) presence of acuity services [23-26, 29, 31-33, 35]. The staffing characteristics included: 1) staffing ratios; 2) behavioral health (BH) expertise; and 3) social services support [16, 20, 26, 32, 33, 36, 37]. Occupancy characteristics involved the resident mix and occupancy rate $[20,24,26,32,33,35]$. Market characteristics associated with APM use in nursing homes included competition and chain membership [24]. Finally, the two quality characteristics associated with higher use were 1) facilities subject to the reporting of physical restraints and 2) facilities with a higher number of deficiencies [21, 32, 38].

Several facility characteristics were reported more frequently than others in our included studies. The positive associations between both lower RN staffing and increasing facility share of Medicaid residents with APM use were each reported in four different studies (Table 3) $[24,26,32,33,35,36]$. Also, the associations between APM use and each of the characteristics: geographical location and for-profit status were shown in five separate studies [23-26, 32, 33, 35].

\section{Discussion}

The purpose of the current systematic review was to study the association between facility characteristics and the use of APM among older adults residing in U.S. nursing homes. Facility-based characteristics that are associated with APMs use in U.S. nursing homes may be categorized into several domains: 1) physical, 2) staffing, 3) occupancy, 4) market, and 5) quality (Table 3).

The current systematic literature review revealed many facility level characteristics that play a role in increasing the use of APMs in the nursing home population. Investigating these characteristics is important because variation based upon facility characteristics could indicate the absence of a nationally consistent and systematic approach to the use of APMs in nursing homes. In order to inform possible interventions to reduce the unnecessary use of APMs, it is important to understand the associated domains of the characteristics as well as the possible reasoning behind the increased use. The complete list of explanations for increased APM use based upon each characteristic are specified in Table 3.

\section{Physical characteristics}

The physical characteristics associated with APM use included physical location, facility size, business type, and the presence of acuity services. Regional variation in APM use was evident with a positive association between APM use and facility location in the central south or northeast U.S. regions [23, 25, 26, 29]. However, one study by Briesacher et al., 2005 expressed a negative association between APM use and nursing homes in the southern United States [22]. It was also found that facilities in the southern U.S. tended to prescribe conventional APMs whereas facilities in the northeastern U.S. prescribed atypical APMs [27]. This positive association between APMs and facilities in the south or northeast U.S. regions could be due to different state laws and regulation or regionally differing treatment approaches of behavioral symptoms of dementia. A positive association between metropolitan location and APM use was evident and these facilities were more likely to prescribe atypical APMs [27, 35]. Increased facility size was conversely negatively associated with APM use, indicating that larger facilities may have more ability to implement change processes or provide more comprehensive services as a result of economies of scale [25, 26, 29]. Larger facilities were also more likely to prescribe atypical APMs rather than conventional [27]. Five articles included evidence that for-profit facilities were positively associated with APM use [24, 26, 31-33]. Kamble et al. found a positive association between the off-label use of APMs and non-profit facilities [30]. Finally, the presence of acuity services was positively associated with the use of APMs, possibly due to larger proportion of residents with more complex medical conditions and behavioral symptoms [26]. Huybrechts et al. found that facilities with Alzheimer special care units more often prescribed atypical APMs [27].

\section{Staffing characteristics}

Staffing characteristics play a pivotal role in the increased use of APMs in nursing homes and include: 1) staffing ratios; 2) the presence of mental health professionals or physicians; and 3) the presence of social services (Table 3). Registered nurse (RN) staffing plays a critical role in the increased use of antipsychotics with a positive association between decreased RN staffing and APM use [26, 32, 33, 36]. Less time is available per patient when nursing staff to patient ratios are low, and APMs may serve as a cost-saving alternative to hiring additional RNs. Interestingly, licensed practical nurse (LPN) to patient ratios have the opposite effect on the use of antipsychotics. A positive relationship between LPNs and APMs exists [32]. We theorize that the difference in training between an LPN and RN could play a role in such association.

In addition to nurse staffing ratios, the presence of mental health professionals, physicians and social services all affect the use of APMs with the presence of mental health professionals positively associated with APM use [20, 26, 32]. Facilities with mental health staff were also more likely to prescribe atypical APMs [27]. 
This positive association could be explained by a greater percentage of residents with behavioral problems in nursing homes where mental health professionals are more available or to the practice patterns of mental health professionals and physicians. Conversely, the presence of social services was negatively associated with the use of APMs. This may be caused by increased patient-clinician face time or by the inclusion of the family in decision-making [20]. It is important to note that Lucas et al. found no association between the presence of mental health staff and APM use [32]. A complete list of staffing characteristics and etiologies of use can be found in Table 3. Overall, it appears that the more time that staff is able to spend with the patients in nursing homes, the less likely it is that APMs are used.

\section{Occupancy characteristics}

Both the resident mix and occupancy rate of a facility contributed to variation of APM use among facilities $[20,24,26,32,33,35]$. Facilities with a greater facility share of Medicaid residents were positively associated with APM use [24, 26, 32, 35]. Medicaid reimbursement rates are on average $70 \%$ of private-pay reimbursement rates and considerably influence the resources available in nursing homes [40]. Consequently, APMs may be used to minimize resource use, or be used as a result of lower staffing levels or insufficient training. Kamble et al. found, however, that Medicaid patients were negatively associated with off-label APM use [30]. Low occupancy rate was positively associated with APM use, again probably due to a decreased availability of funds to increase staffing, education and/or training [26]. It may be reasonable to assume that the quality of care goes down when facility care capacities are exceeded. Also, a lower Medicare census, increased racial diversity, and self-pay patients were positively associated with APM use according to several studies [20, 30, 33, 35]. Finally, it is important to note that one study found that payment source does not affect the use of APMs [28]. The occupancy characteristic etiologies of increased APM use were commonly related to fewer resources and limited funding.

\section{Market characteristics}

Two market characteristics, independent ownership and minimal competition, were positively associated with use of APMs in U.S. nursing homes [24]. Competition may reduce APM use by forcing nursing homes to improve or maintain higher quality to maintain occupancy. Independent ownership may contribute to increased rates of use as a result of a lack of standardization, accountability and oversight [24]. Interestingly, Pimentel et al. found that pharmaceutical marketing was not significantly associated with the use of antipsychotics [34].

\section{Quality characteristics}

Facilities subject to reporting physical restraint use and with higher numbers of deficiency citations were positively associated with APM use [21, 32, 38]. Requiring nursing homes to report physical restraints was positively associated with APM use, possibly due to the fact that APMs, presumed to have fewer adverse effects, were used as a substitute [38]. The number of citations received at a nursing home was also positively associated with APM use [32]. It has been previously shown that lower quality is associated with increased citations $[21,32]$. It is possible that the nursing homes might have a multitasking incentive problem, wherein the efforts to improve quality are spread to many areas of concern and could lead to not adequately addressing the use of APMs [21].

\section{Policy and management implications}

Despite multiple legislative and educational interventions, including the 1987 Omnibus Budget Reconciliation Act's Nursing Home Reform Law, the FDA's black box warning on antipsychotic medications, the Centers for Medicare and Medicaid Services campaign to decrease the use of antipsychotics in nursing homes nationwide, and the Nursing Home Compare website related to antipsychotics, it is clear that much work remains to be done. It is a promising sign however, that the government initiatives have influenced and increased research surrounding the topic. The majority of the studies included in this review were published between 2006 and 2012 after the black box warning was issued. Many of these studies focus on the facility characteristics included in the national OSCAR database, which surveys revenue sources, ownership, staffing, resident mix and deficiency reporting. The studies published after 2012, the year CMS launched an initiative to decrease use, investigate additional nursing home characteristics that influence APM use including: consultant psychiatry, pharmaceutical marketing, physical restraint deficiency reporting, and the presence of social services (Additional file 3). All of these studies provide valuable information about the use of APMs in the nursing home population in the U.S. Policy and management interventions to reduce the unnecessary use of APMs in elderly nursing home patients should focus on the facility and quality characteristics associated with use and address the root causes of excessive use of these dangerous drugs. The variation in use based upon staffing, market, physical, and quality characteristics of the nursing homes illustrates the need for a strict and systematic approach to APM use. Facility characteristics discussed in this review could inform meaningful and evidence-based interventions that would result in reduced use of APMs 
and the serious and poor health outcomes associated with their use.

\section{International implications}

The findings of this literature review can benefit an international audience, as high rates of APM use in nursing homes are common not only in the U.S. but in other nations as well. Although skilled nursing care can differ between nations, the facility characteristics affecting the use of APMs may be similar. Understanding the facility characteristics affecting use of these drugs in nursing homes can help inform policies and research internationally. It is crucial to consider the potential causes of overuse. In a campaign to reduce use in England, it was noted that although good practice guidelines are available, there has not been a clear integration into clinical practice [13]. Looking at the facility characteristics may help to provide insight into the difficulties of translating clinical guidelines into practice. It is important to look at international approaches to the use of APMs in the treatment of patients with dementia in order to find the safest and most effective treatment for this population.

\section{Limitations}

This study has several important limitations. First, the studies included in the review did not sample the same population; some included national data and others data from a single state. Second, it was difficult to systematically judge the quality of the articles because observational studies of several varieties were included. Finally, the expert consultant panel used in the modified Delphi process was comprised of providers from limited geographical areas (Arizona, Washington, Pennsylvania, Illinois, South Carolina and Oregon). This may have resulted in APM use etiology suggestions consistent with nursing homes in those areas, which may have differed from other regions. Surveying health professionals across the nation would result in a more representative and potentially less biased perspective. Importantly, this review was constrained to facility level features, many of which are not remediable.

\section{Conclusion}

The use of APMs in U.S. nursing homes was found to vary based on physical, staffing, occupancy, market, and quality characteristics. Due to the dangerous health outcomes associated with use of APMs in the elderly, it is critical that unnecessary use be reduced. The facility characteristics outlined in this review may serve as a basis for meaningful interventions to improve the quality of care in nursing homes across the nation and abroad.

\section{Additional file}

Additional file 1: Database search strategies. (DOCX $32 \mathrm{~kb}$ )

Additional file 2: PRISMA checklist. (DOCX $22 \mathrm{~kb}$ )

Additional file 3: Table of included studies by time period. (DOCX $25 \mathrm{~kb}$ )

\section{Abbreviations}

APM: Antipsychotic medication; BH: Behavioral health; CMS: Centers for medicare and medicaid services; FDA: Food and drug administration; LPN: Licensed practical nurse; MDS: Minimum data set; OSCAR: Online survey certification and reporting; PRISMA: Preferred reporting items for systematic reviews and meta-analyses; RN: Registered nurse; STROBE: Strengthening the reporting of observational studies in epidemiology; U.S.: United States

\section{Acknowledgements \\ None. \\ Funding \\ This research received no specific grant from any funding agency in the public, commercial, or not-for-profit sectors.}

Availability of data and materials

All data generated or analyzed during this study are included in this published article (and its supplementary information files).

\section{Authors' contributions}

HC made substantial contributions to the design of the review, acquisition of the data as first reviewer during the PRISMA process, interpreting the data, and drafting the manuscript. SA was the second reviewer during the PRISMA process, made substantial contributions to concept and design of the review, and was a major contributor in writing the manuscript. $\mathrm{CH}$ conducted all literature searches, made substantial contributions to the concept and design of the review, was the third reviewer during the PRISMA process, and was involved in drafting the manuscript. JL made substantial contributions to the analysis and interpretation of the studies and was involved in revising the manuscript critically for important intellectual content. MF made substantial contributions to the concept and design of the review and was involved in revising the manuscript critically for important intellectual content. HE made substantial contributions to the concept and design of the review and was involved in revising the manuscript critically for important intellectual content. KS made substantial contributions to the concept and design of the review and was involved in revising the manuscript critically for important intellectual content. JM made substantial contributions to the concept and design of the review, to the analysis and interpretation of the studies and was involved in drafting the manuscript. All authors read and approved the final manuscript.

Competing interests

The authors declare that they have no competing interests.

Consent for publication

Not applicable.

Ethics approval and consent to participate Not applicable.

\footnotetext{
Author details

${ }^{1}$ College of Public Health, University of Arizona, Tucson, Arizona, USA ${ }^{2}$ Arizona Center on Aging, College of Medicine, University of Arizona, Tucson, Arizona, USA. ${ }^{3}$ College of Pharmacy, University of Arizona, Tucson, Arizona, USA. ${ }^{4}$ University of Arizona Health Sciences Library, Tucson, USA. ${ }^{5}$ Division of Geriatrics, General Internal Medicine and Palliative Medicine, College of Medicine, University of Arizona, Tucson, Arizona, USA.
} 


\section{References}

1. Nursing Home Reform Law, 42 U.S.C. §§1395i-3(a)-(h), 1396r(a)-(h) In. Edited by (Medicare and Medicaid r; 1987.

2. Kuehn BM. FDA warns antipsychotic drugs may be risky for elderly. JAMA. 2005;293(20):2462-2

3. Levinson DR, Pattison BT, Walden DK. Medicare atypical antipsychotic drug claims for elderly nursing home residents: US department of health and human services, office of inspector general. 2011.

4. Bonner A. Improving dementia care and reducing unnecessary use of antipsychotic medications in nursing homes. Baltimore: Center for Medicare and Medicaid Services, ed Medicare Learning Network; 2013.

5. Services TCFMM. Partnership to Improve Dementia Care in Nursing Homes. Antipsychotic Drug use in Nursing Homes Trend Update. In.; 2014

6. Ortman JM, Velkoff VA, Hogan $\mathrm{H}$. An aging nation: the older population in the United States. Washington: US Census Bureau; 2014. p. 25-1140.

7. Health UDo, Services H. Long-term care services in the United States: 2013 Overview. 2013.

8. Alexander GC, Gallagher SA, Mascola A, Moloney RM, Stafford RS. Increasing off-label use of antipsychotic medications in the United States, 1995-2008. Pharmacoepidemiol Drug Saf. 2011;20(2):177-84

9. AfHR Q. Off-label use of atypical antipsychotic drugs: a summary for clinicians and policymakers. 2007.

10. Chiu Y, Bero L, Hessol NA, Lexchin J, Harrington C. A literature review of clinical outcomes associated with antipsychotic medication use in North American nursing home residents. Health Policy. 2015;119(6):802-13.

11. Fossey J, Ballard C, Juszczak E, James I, Alder N, Jacoby R, Howard R. Effect of enhanced psychosocial care on antipsychotic use in nursing home residents with severe dementia: cluster randomised trial. BMJ. 2006; 332(7544):756-61.

12. Issues bulletin. The use of medicines in dementia care. London: IMS Health; 2009.

13. Banerjee $\mathrm{S}$. The use of antipsychotic medication for people with dementia: Time for action. London: Department of Health; 2009.

14. Janus SI, van Manen JG, IJzerman MJ, Zuidema SU. Psychotropic drug prescriptions in Western European nursing homes. International psychogeriatrics. 2016;28(11):1-16.

15. Maher AR, Maglione M, Bagley S, Suttorp M, Hu J-H, Ewing B, Wang Z, Timmer M, Sultzer D, Shekelle PG. Efficacy and comparative effectiveness of atypical antipsychotic medications for off-label uses in adults: a systematic review and meta-analysis. JAMA. 2011:306(12):1359-69.

16. Ray WA, Chung CP, Murray KT, Hall K, Stein CM. Atypical antipsychotic drugs and the risk of sudden cardiac death. N Engl J Med. 2009;360(3):225-35.

17. Schneider LS, Dagerman KS, Insel P. Risk of death with atypical antipsychotic drug treatment for dementia: meta-analysis of randomized placebo-controlled trials. JAMA. 2005;294(15):1934-43.

18. Liberati A, Altman DG, Tetzlaff J, Mulrow C, Gøtzsche PC, loannidis JP, Clarke M, Devereaux PJ, Kleijnen J, Moher D. The PRISMA statement for reporting systematic reviews and meta-analyses of studies that evaluate health care interventions: explanation and elaboration. Ann Intern Med. 2009;151(4):W-65-94

19. Von Elm E, Altman DG, Egger M, Pocock SJ, Gøtzsche PC, Vandenbroucke $J P$, Initiative $S$. The strengthening the reporting of observational studies in epidemiology (STROBE) statement: guidelines for reporting observational studies. Prev Med. 2007;45(4):247-51.

20. Bonner AF, Field TS, Lemay CA, Mazor KM, Andersen DA, Compher CJ, Tjia J, Gurwitz JH. Rationales that providers and family members cited for the use of antipsychotic medications in nursing home residents with dementia. J Am Geriatr Soc. 2015;63(2):302-8.

21. Bowblis JR, Crystal $\mathrm{S}$, Intrator $\mathrm{O}$, Lucas JA. Response to regulatory stringency: the case of antipsychotic medication use in nursing homes. Health Econ. 2012;21(8):977-93.

22. Briesacher BA, Limcangco MR, Simoni-Wastila L, Doshi JA, Levens SR, Shea DG, Stuart B. The quality of antipsychotic drug prescribing in nursing homes. Arch Intern Med. 2005:165(11):1280-5.

23. Briesacher BA, Tjia J, Field T, Peterson D, Gurwitz JH. Antipsychotic use among nursing home residents. JAMA. 2013;309(5):440-2.

24. Castle NG, Hanlon JT, Handler SM. Results of a longitudinal analysis of national data to examine relationships between organizational and market characteristics and changes in antipsychotic prescribing in US nursing homes from 1996 through 2006. American J Geriatric Pharmacotherapy. 2009;7(3):143-50.
25. Chen Y, Briesacher BA, Field TS, Tjia J, Lau DT, Gurwitz JH. Unexplained variation across US nursing homes in antipsychotic prescribing rates. Arch Intern Med. 2010;170(1):89-95.

26. Hughes CM, Lapane KL, Mor V. Influence of facility characteristics on use of antipsychotic medications in nursing homes. Med Care. 2000;38(12):1164-73.

27. Huybrechts KF, Rothman KJ, Brookhart MA, Silliman RA, Crystal S, Gerhard T, Schneeweiss $S$. Variation in antipsychotic treatment choice across US nursing homes. J Clin Psychopharmacol. 2012;32(1):11-7.

28. Kamble P, Chen H, Sherer J, Aparasu RR. Antipsychotic drug use among elderly nursing home residents in the United States. American J Geriatric Pharmacotherapy. 2008;6(4):187-97

29. Kamble $P$, Chen $H$, Sherer JT, Aparasu RR. Use of antipsychotics among elderly nursing home residents with dementia in the US: an analysis of national survey data. Drugs Aging. 2009;26(6):483-92.

30. Kamble P, Sherer J, Chen H, Aparasu R. Off-label use of second-generation antipsychotic agents among elderly nursing home residents. Psychiatr Serv. 2010;61(2):130-6.

31. Lester P, Kohen I, Stefanacci RG, Feuerman M. Antipsychotic drug use since the FDA black box warning: survey of nursing home policies. J Am Med Dir Assoc. 2011;12(8):573-7.

32. Lucas JA, Chakravarty S, Bowblis JR, Gerhard T, Kalay E, Paek EK, Crystal S. Antipsychotic medication use in nursing homes: a proposed measure of quality. Int J Geriatr Psychiatry. 2014;29(10):1049-61.

33. Miller SC, Papandonatos G, Fennell M, Mor V. Facility and county effects on racial differences in nursing home quality indicators. Soc Sci Med. 2006; 63(12):3046-59.

34. Pimentel CB, Donovan JL, Field TS, Gurwitz JH, Harrold LR, Kanaan AO, Lemay CA, Mazor KM, Tjia J, Briesacher BA. Use of atypical antipsychotics in nursing homes and pharmaceutical marketing. J Am Geriatr Soc. 2015:63(2):297-301.

35. Stevenson DG, Decker SL, Dwyer LL, Huskamp HA, Grabowski DC, Metzger ED, Mitchell SL. Antipsychotic and benzodiazepine use among nursing home residents: findings from the 2004 National Nursing Home Survey. Am J Geriatr Psychiatr. 2010;18(12):1078-92.

36. Svarstad BL, Mount JK, Bigelow W. Variations in the treatment culture of nursing homes and responses to regulations to reduce drug use. Psychiatr Serv. 2001;52(5):666-72.

37. Tjia J, Field T, Lemay C, Mazor K, Pandolfi M, Spenard A, Ho SY, Kanaan A, Donovan J, Gurwitz JH, et al. Antipsychotic use in nursing homes varies by psychiatric consultant. Med Care. 2014;52(3):267-71.

38. Konetzka RT, Brauner DJ, Shega J, Werner RM. The effects of public reporting on physical restraints and antipsychotic use in nursing home residents with severe cognitive impairment. J Am Geriatr Soc. 2014;62(3):454-61

39. Zhang NJ. National Quality Measurement Systems for Assessment of Nursing Home Care. 2009.

40. Grabowski DC. A longitudinal study of Medicaid payment, private-pay price and nursing home quality. Int J Health Care Finance Econ. 2004;4(1):5-26.

\section{Submit your next manuscript to BioMed Central and we will help you at every step:}

- We accept pre-submission inquiries

- Our selector tool helps you to find the most relevant journal

- We provide round the clock customer support

- Convenient online submission

- Thorough peer review

- Inclusion in PubMed and all major indexing services

- Maximum visibility for your research

Submit your manuscript at www.biomedcentral.com/submit 